\title{
Exclusion of married adolescents in a study of gestational diabetes mellitus: a case study
}

\author{
Mala Ramanathan ${ }^{1 *}$ and K. Sakeena ${ }^{2}$ \\ From Global Forum on Bioethics in Research (GFBR)'s "Ethics of Research in Pregnancy" meeting \\ Buenos Aires, Argentina. 03-04 November 2016
}

\begin{abstract}
A study on gestational diabetes mellitus (GDM) among 200 married women in Malappruam, Kerala, India, chose to exclude married women below the age of 18 from participation. Marriages before age 18 are not considered legally valid and persons below age 18 do not have the status of an adult. Parents are considered the legal guardians of married women under age 18, but because marriages are patrilocal, obtaining consent from parents would have time costs. Further, obtaining parental consent may also be considered disrespectful of the in-laws. The inclusion of married adolescents in this study was considered difficult for these reasons. This exclusion can also result in wrongly estimating the levels of GDM among all women at risk. We argue that such exclusion is also unethical; it unfair to exclude women who stand to benefit from participation by enabling them to identify the enhanced life time risk for diabetes mellitus and monitor their future health status better. Recognizing married adolescents as emancipated minors would enable their participating without violating confidentiality regarding their GDM status to parents and in-laws.
\end{abstract}

Keywords: Gestational diabetes mellitus, Adolescent women, Unfair exclusion, Confidentiality, Mature minors

\section{Case background}

According to the District Level Household Surveys 4, which provide reproductive and child health-related data up to the district level in India, $24.7 \%$ of adult women aged $\geq 18$ in Kerala reported blood sugar levels $>140 \mathrm{mg} / \mathrm{dl}$ and $13.5 \%$ reported blood sugar levels $>160 \mathrm{mg} / \mathrm{dl}$ [1]. For the district of Malappuram (within the state of Kerala), $14 \%$ of the women aged $\geq 18$ reported blood sugar levels $>140 \mathrm{mg} / \mathrm{dl}$ and $7.1 \%$ reported levels $>160 \mathrm{mg} / \mathrm{dl}$ [2]. The burden of diabetes mellitus among adult women motivated a public health study on post-partum diabetes screening and follow-up for women with gestational diabetes mellitus (GDM) in the district of Malappuram (K Sakeena: Patterns of and factors associated with postpartum diabetes screening in women

\footnotetext{
* Correspondence: mala@sctimst.ac.in

${ }^{1}$ AMCHSS, Sree Chitra Tirunal Institute for Medical Sciences and Technology,

Trivandrum, India

Full list of author information is available at the end of the article
}

diagnosed with gestational diabetes mellitus in Malappuram district, unpublished).

The primary objectives of this study were to examine the patterns of and factors associated with post-partum diabetes among women who had GDM during their most recent pregnancy and to document post-partum morbidity among these women. A secondary objective was to understand health providers' perspectives on appropriate followup care for patients who had experienced GDM.

The study design used a mixed methods approach that included (i) a cross-sectional survey with a structured interview schedule for the GDM patients and (ii) in-depth interviews (using an interview guide) for health providers. The sample size for the study was 200 married women diagnosed with GDM during their most recent pregnancy in selected hospitals. The women included in the study were to have delivered three to 6 months before the date on which the survey was administered to ensure that all participants had a minimum of 9 weeks of post-partum 
experience to include in the morbidity study. Adolescent married women were excluded from participation due to researcher concerns that parental consent would be difficult to obtain and that obtaining parental consent would be considered disrespectful of the in-laws.

\section{Ethical discussion}

\section{Unfair exclusion criteria}

The study on GDM in Malappuram district chose to exclude married women below age 18 from participation. This pragmatic approach to the research unfairly excluded a group of women and their children who are particularly vulnerable to getting diabetes mellitus. These young women and their children would benefit from screening and advice on lifestyle modification to manage or to prevent diabetes mellitus. The original study was designed to include 200 married women of all ages diagnosed with GDM during their most recent pregnancy in selected hospitals. The inclusive age range was important as GDM can affect all women who get pregnant and, in India, pregnancy generally tends to follow marriage. Other studies have shown that the risk of GDM follows the risk of type 2 diabetes mellitus in most populations and is associated with higher maternal age. Such risk among Asians was higher in the United States and Europe [3]. As the risk of pregnancy among women in younger ages is lower in North America and Europe, it is possible that reported prevalence of GDM could also be affected by the smaller share of pregnant women in younger ages. Even so, two out of every 100 teenaged pregnant women did develop GDM in the United States, and this risk is highest among Asian/Pacific Islander adolescent women when compared to non-Hispanic whites [4]. Therefore, including women of all ages within the reproductive span is extremely important as a matter of fairness.

Despite this strong rationale, the study team faced significant challenges with the recruitment of married women under the age of 18 because such marriages are not legally recognized. In India, the Prohibition of Child Marriage Act stipulates that the legal age for marriage is 18 for females and 21 for males [5]. In the state of Kerala-a state known for high levels of literacy in general (and female literacy in particular), better access to healthcare, and relatively higher ages at marriage-the prevalence of child marriage involving females under the age of 18 was $2.8 \%$ in $2012-13$ [1]. However, in the Malappuram district-the most densely populated of the 14 districts of Kerala and the district with the highest population growth rates-the prevalence of child marriage involving adolescent girls under the age of 18 was $26.3 \%$ during this same time period and the percentage of all births in Malappuram to women between the ages of $15-19$ years in $2012-13$ was $6.2 \%[2]$.

\section{Consent for emancipated minors}

Typically, participation in research requires informed consent from adults (and emancipated minors) and assent from minors. In India, persons below the age 18 are not considered legal adults and the concept of emancipated minor is not legally recognized [6]. For this reason, research involving married adolescent girls is difficult with regard to consent.

Current practice in India is that ethics committees require the assent of married adolescent girls and the consent of their legal guardians [7]. Legal guardians of females below age 18 are nominally their parents. The problem with obtaining consent from the parents is that after the marriage, most girls move to their affinal homes and live with their husbands and in-laws. Neither the husband (assuming he is above the age of 18) nor the in-laws are recognized as legal guardians.

These practical difficulties involved in obtaining consent from the legal guardians (the parents) lead to the exclusion of married women below age 18 in the study. Seeking consent from the parents was a legal option, but might have been seen as disrespectful of the marriage (even though the law does not recognize the marriage of girls below age 18). Moreover, attempting to obtain such consent was not without a time cost. Consent from parents or in-laws would also violate confidentiality requirements for the young women as the purpose of the study would have to be mentioned to those giving consent.

\section{Conclusions}

Studies on the reproductive health of adolescents require that confidentiality be respected, even if consent for participation is obtained from parents or legal guardians [8]. Ethics committees in India have allowed for a young adolescent to identify an adult living in her household whom she identifies as having her welfare at heart to provide consent on her behalf (Vivek RV: Healthcare seeking behaviour among female adolescents for reproductive morbidities in the urban slums of Chandigarh, unpublished). Making such an allowance for studies among married adolescents, particularly when they will directly benefit from such participation - as in the case of GDM where knowledge of the condition would enable the women to better participate in follow-up care-is one possible solution to this unfair exclusion. Such a policy has implications for studies elsewhere in India where the proportion of women married before age 18 is likely to be even higher than that found in Malappuram. In such circumstances, exclusions due to the difficulties in 
overcoming cultural barriers would affect the outcome measure and also exclude far more women than would happen in situations where marriages before age 18 are fewer in number. However, this solution would not respect confidentiality requirements.

Alternatively, if there is recognition of a married adolescent as a mature minor, this form of unfair exclusion can be avoided. In low- and middle-income countries, where married adolescents and/or pregnant adolescents are most likely to be found and benefit from engagement in research, lack of such recognition is problematic and often unfair. Recognition of a married adolescent as a mature minor would prevent this form of unfair exclusion and also serve to address issues relating to maintaining confidentiality regarding the young woman's GDM status.

\section{Abbreviations}

GDM: Gestational diabetes mellitus

\section{Acknowledgements}

This paper has benefited from comments on earlier versions from Prof. Françoise Baylis, Dalhousie University, Halifax, Nova Scotia and Prof. Maureen Kelley, Ethox Centre, University of Oxford and two anonymous reviewers. Comments from other participants at the meeting on Ethics of Research in Pregnancy in Buenos Aires also were useful in identifying potential solutions to the ethical dilemmas. However, the errors, if any, in the presentation are our own.

\section{Funding}

Funds for presenting this case study at the Global Forum for Bioethics in Research's Ethics of Research in Pregnancy meeting in Buenos Aires were made available by the Wellcome Trust. The publication cost of this article was funded by the Wellcome Trust.

\section{Availability of data and materials}

Data cited are publicly available from the Census of India 2011 and also from the cited health surveys.

\section{About this supplement}

This article has been published as part of Reproductive Health Volume 14 Supplement 3, 2017: Proceedings from the Global Forum on Bioethics in Research (GFBR)'s "Ethics of Research in Pregnancy" meeting. The full contents of the supplement are available online at https://reproductive-healthjournal.biomedcentral.com/articles/supplements/volume-14-supplement-3.

\section{Authors' contributions}

KS conceptualized and undertook the original study on which this case study on bioethics is based. MR identified the key ethical issues and wrote the first draft. KS reviewed and provided inputs for various revisions. MR undertook the revisions and compiled the final draft. MR and KS have read and approved the final manuscript. MR is the corresponding author.

\footnotetext{
Authors' information

Mala Ramanathan is Professor at AMCHSS, Sree Chitra Tirunal Institute for Medical Sciences and Technology, Trivandrum, India. Email:

mala@sctimst.ac.in

K Sakeena, was an MPH Student at AMCHSS, SCTIMST during the drafting of this case study and is currently Deputy Director, Kerala Health Services,

Kerala, India. Email: drksakeena@gmail.com
}

\section{Ethics approval and consent to participate}

This study was reviewed by the Institutional Ethics Committee of the Sree Chitra Tirunal Institute for Medical Sciences and Technology, Trivandrum. Written informed consent was obtained from individual participants.
Consent for publication

Not applicable

\section{Competing interests}

The authors declare that they have no competing interests.

\section{Publisher's Note}

Springer Nature remains neutral with regard to jurisdictional claims in published maps and institutional affiliations.

\section{Author details}

${ }^{1}$ AMCHSS, Sree Chitra Tirunal Institute for Medical Sciences and Technology, Trivandrum, India. ${ }^{2}$ Kerala Health Services, Kerala, India.

Published: 14 December 2017

\section{References}

1. IIPS. Kerala, state fact sheet: district level household and facility survey (2012-13). Mumbai: MOHFW; 2014. GOl. http://rchiips.org/pdf/dlhs4/report/ KE.pdf. Accessed 20 May 2016.

2. IIPS. Mallappuram, district fact sheet: district level household and facility survey (2012-13). Mumbai: MOHFW; 2014. GOI. Accessed 20 May 2016.

3. Ferrara A. Increasing prevalence of gestational diabetes mellitus: a public health perspective. Diabetes Care. 2007;30:S141-6.

4. Lawrence JM, Chen W, Contreras R, Sacks DA. Trends in the prevalence of preexisting diabetes and gestational diabetes mellitus among a racially/ ethnically diverse population of pregnant women, 1999-2005. Diabetes Care. 2008;31:899-904.

5. Ministry of Law and Justice. Prohibition of child marriage act. 2006. Issued by: Government of India, No. 6 of 2007. http://ncw.nic.in/acts/pcma2006.pdf. Accessed 30 Sept 2016.

6. The Indian Majority Act. Act 9 of 1875. The Indian Majority Act, 1875. http:// indiacode.nic.in/fullact1.asp?tfnm=187509. Accessed 20 Sept 2016.

7. Indian Council of Medical Research. Ethical guidelines for biomedical research on human participants. New Delhi: ICMR; 2006. http://www.icmr. nic.in/ethical_guidelines.pdf. Accessed 30 Sept 2016.

8. World Health Organization. Ethical issues. In: Reproductive health involving adolescents, scientific and ethical review group. http://www.who.int/ reproductivehealth/topics/ethics/adolescents_guide_serg/en/. Accessed 12 Oct 2016

Submit your next manuscript to BioMed Central and we will help you at every step:

- We accept pre-submission inquiries

- Our selector tool helps you to find the most relevant journal

- We provide round the clock customer support

- Convenient online submission

- Thorough peer review

- Inclusion in PubMed and all major indexing services

- Maximum visibility for your research

Submit your manuscript at www.biomedcentral.com/submit
Ciomed Central 